\title{
A CRITIQUE OF THE IMPACT OF CONSUMER DISSATISFACTION
}

\author{
Portia Opoku Boadi \\ Harbin Institute of Technology, 92 West Xidazhi street Harbin, P.R.China \\ Li Guoxin \\ Harbin Institute of Technology, 92 West Xidazhi street Harbin, P.R.China \\ Andrew Adjah Sai \\ Estonian Business School, 10114 Tallin, Estonia \\ Philip Antwi \\ Harbin Institute of Technology, 92 West Xidazhi street Harbin, P.R.China
}

\begin{abstract}
Research into consumer satisfaction levels have gone far enough for several years now, however, much has not been done to reiterate how consumers will react and deal with their dissatisfaction and the effect it has on the companies. The main objective of this paper was to review literature that depicts the impact that dissatisfaction has on consumers based on existing theoretical literature. The focus of this study is mainly to know how far a consumer is willing to go when dissatisfied with a product or service, in effect, weighing all the pros and cons of consumer dissatisfaction. This review paper combines the results of previous studies conducted on consumer dissatisfaction. The major consequences of consumer dissatisfaction discussed in this paper include negative Word-of-mouth, switch, complaints and no co-creation intentions. One major finding of this study is that all literature on consumer satisfaction relates it with consumer dissatisfaction by using several theories to explain a consumer's judgement after consuming a product or service.
\end{abstract}

Keywords: Co-creation intention, complaints, consumer dissatisfaction, negative Word-of mouth (WOM)

JEL code: M31

\section{Introduction}

Every consumer at one point in time has experienced dissatisfaction, either with a product or a service. However there are few researches on consumer dissatisfaction, as most articles focus on consumer satisfaction. According to Oliver (1997), dissatisfaction can be interpreted as the unpleasant experience that one gets from using a product or service after usage. (Oliver, 1997) Before purchase, every consumer has an expected outcome. Thus, if this expected outcome is not attained then the consumer becomes dissatisfied. Several theories have been proposed to explain consumer satisfaction and in all of these theories, there is a distinction between the expectation before use and the actual performance after use. It is at this point that a consumer can decide whether he/she is satisfied or dissatisfied. Since consumers are aware that it is the duty of 
companies and service providers to cater for their needs especially when they have paid for it, they exhibit several attitudes towards dissatisfaction. As a matter of fact, according to Landon Jr, (1997) companies, government agencies and most consumers are keen to find out the results of consumer satisfaction and dissatisfaction. (Landon Jr, 1977) The more satisfied consumers become the more profits the companies will make. The government also through consumer satisfaction can advance the social well-being of the people and finally consumers can make informed decisions when they are aware of how other users of the same product or service have been satisfied or dissatisfied (Bodur, 1977). When consumers are satisfied it has a positive impact on companies as they incur high profits, consumers will spread positive word of mouth and continue purchasing their products (Oliver Richard, 1997). On the other hand when dissatisfied, consumers might stop repurchase, spread negative word of mouth, complain and even return products (Cadotte and Turgeon, 1988). As consumer dissatisfaction has a negative impact, companies are very careful in their dealings so as to avoid dissatisfaction among consumers. Some of the impacts of dissatisfaction to be discussed include Complaints, Negative Word of Mouth, Switching intentions, Inertia, disappointment, regret and no co-creation intentions. The objective of this article is to outline the impact of dissatisfaction on consumers in relation to their responses to dissatisfaction by reviewing what other researchers have come up with.

\section{Theoretical background}

\subsection{Consumer dissatisfaction}

As long as consumer expectation is higher than actual experience after the use of a product or service, dissatisfaction will set in. Webster and Sundaram (1998) asserts that when there is a tremendous decline in service, dissatisfaction is bound to occur (Webster and Sundaram, 1998). When consumers are dissatisfied with a product or service they become very emotional and they exhibit all kinds of behaviors such as regrets and feelings of disappointment (Jang and Kim, 2011). Many researchers have come up with dissatisfaction behavior that consumers portray. As asserted by Ferguson and Johnston, (2011) it is obvious that a consumer's decision to re-purchase a product or service is highly dependent on the experiences in the past with the same product or service (Ferguson and Johnston, 2011). For instance, (Zeelenberg and Pieters, 2004) established that consumers who are dissatisfied have more reasons to switch products compared to consumers who are satisfied. In their research, Zeelenberg \& Pieters, 2004 emphasizes that the consumer's emotions is directly related to how they will react when dissatisfied. This means that consumers get more dissatisfied when their emotions are negative and are satisfied when their emotions are positive. Again, (Richins, 1983) asserts that dissatisfied consumers complain and spread negative Word of Mouth (WOM). His study focused on why spreading WOM is characterized from all other forms of dissatisfaction behaviors, by identifying the type of dissatisfaction, who the consumer attacks when dissatisfied and the consumer's perception of how the seller would respond to their dissatisfaction.

\subsection{Negative Word of Mouth (WOM)}

In his research, (Buttle, 1998) argues that WOM can be seen in how people are impacted, among workers and hiring as well, however researchers mostly concentrate on the consumer aspect to address what precedes and the effects of WOM. Researchers like (Sheth, 1971) and (Day, 1971) emphasized the importance that WOM is more effective compared to advertising because WOM is considered a more reliable source. However, because WOM has no boundaries, it is considered 
to be different from advertising (Stern, 1994), in this regard, every company takes WOM very seriously as it can make or break their profits. WOM comes in different forms but with the recent inception of information technology, WOM is mostly done virtually through online platforms, and can either be negative or positive based on the consumer's emotions. In most cases of dissatisfaction WOM is negative, and this paper focuses on the negative WOM as an impact of consumer dissatisfaction. According to G Nejad et al. (2015), negative WOM can have serious effect on the profits of a firm whose market involves consumers with different needs and wants, especially as the firm cannot explicitly control WOM (Yadav and Pavlou, 2014). People spread negative WOM when they are not satisfied with a product or service, and this is their own way of preventing other consumers go through what they have been through Xia et al. (2004). With the introduction of social media, consumers often share their bitter experiences on such platforms. The study of Balaji et al. (2016), focused on the reason behind why consumers communicate bitter experiences on social media. Their results showed that certain factors precede negative WOM and such factors can be contingent, could be determined by the individual or the social network. This notwithstanding, dissatisfaction brings about different kinds of intentions. In the research of Casidy and Shin (2015), they emphasized that people who are explicitly involved in dissatisfaction have substantial motives of negative WOM. In effect, when people are not treated fairly or dissatisfied, it can lead to certain attitudes whether or not the person is directly involved in the situation Colquitt (2004).Several researchers like (Buttle, 1998, G Nejad et al., 2015, Xia et al., 2004, Balaji et al., 2016, Casidy and Shin, 2015, Colquitt, 2004) have delved into the subject of Negative WOM

\subsection{Switching intentions}

There have been several studies on consumer switching intentions. Indeed, in most cases dissatisfied consumers are more likely to switch than satisfied consumers as asserted by Loveman (1998). Others like (Antón et al. (2007), Sloot and Verhoef, 2008, Jones et al., 2000, Chih et al., 2012) have as well discussed the subject matter. Switching means the discontinuance of the use of a product or service to another Zeelenberg and Pieters (2004). In this regard, a consumer is more likely to switch to a more preferable alternative that brings better satisfaction.

\subsection{Consumer Complaints}

People complain from being dissatisfied with a product or service. There have been several research undertaken to explain why consumers complain (Hansen et al. (2010), Garrett and Toumanoff, 2010). People choose direct means to complain, such as on company provided platforms or indirect means such as complaining to people who are in no way connected to the product or service. In whichever way that consumers choose to complain, it leaves an effect on the company and its products. In their research, Zeelenberg and Pieters (2004) anticipated that there could be a connection between being disappointed and complaining. Because prior to purchase consumers tend to predict the satisfaction level of consuming a product or service and so if it tends out not to be so, then they are compelled to complain.

\subsection{Inertia}

Sometimes consumers can be passive about dissatisfaction, and this is associated with inertia. In most instances, consumers inertia behaviors are due to the fact that they find it irritating to look for other alternatives as it also requires time and energy Wirtz et al. (2006). Although Oliver 
Richard (1997) asserted that inertia could be way of ensuring consumer loyalty, companies should not rely on it as such behaviors cannot last for longer periods. Other writers have established the vulnerability of the relationship between inertia and consumer loyalty. Again, several studies have linked consumer inertia behaviors to the time, energy and costs associated with finding a different service provider or another product.

\subsection{Research gaps}

Most literature base consumer dissatisfaction on emotions, and the focus of the studies continues to be in the hospitality and service industries which includes mostly hotels and restaurants. In this regard, this review paper adopts a conceptual framework from existing consumer behavior literature to address these gaps.

\section{Conceptual framework}

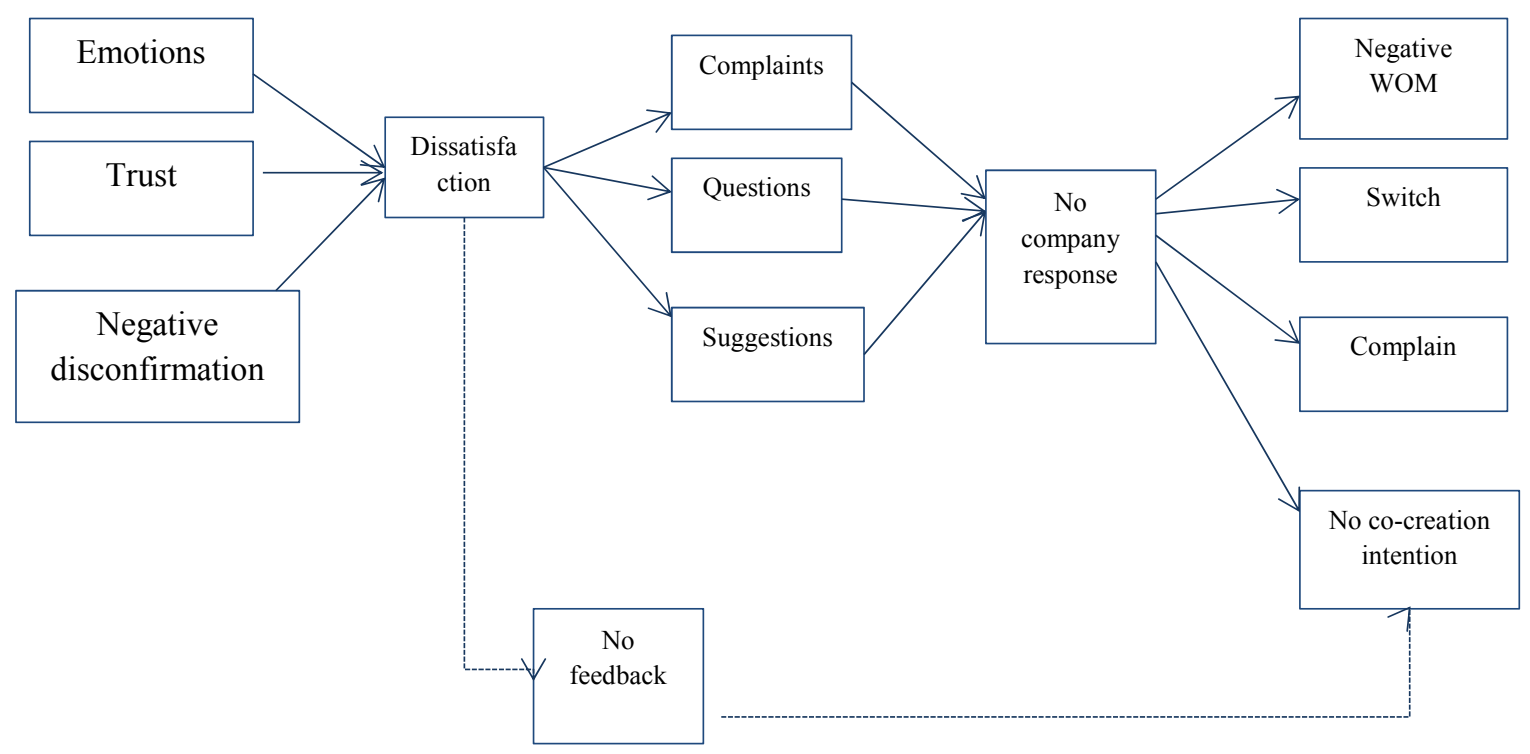

Fig. 1: Conceptual framework

\subsection{Antecedents of dissatisfaction}

\subsubsection{Emotions}

Literature on emotions in relation to consumer satisfaction and dissatisfaction was not really in the known until 1983, when Westbrook presented an empirical work in the direction of consumer satisfaction and dissatisfaction in which he stated that emotions cannot be explained in a specific way as it involves an act in a particular manner. Westbrook used the Izard's differential emotion theory which presents ten different kinds of emotions. Westbrook (1983) came up with a limited idea of the differentia emotions scale and applied it in the automobile setting. In his findings he concluded that emotions that are precise were more preferred than hostile ones. And this validates the ideas that other prior literature contributed on consumer satisfaction and dissatisfaction. However, his methods predicted a fluctuating alliance in relation to factors 
associated with emotions. Currently, theories on emotions posit that perception and intuition results in unequivocal feelings, as and when it becomes profitable and vice versa. Per this notion, consumer dissatisfaction will be seen as a "negative emotion" based on a consumer's anticipation of how a product or service will work out as against how it actually works out after utilization. R. L. Day (1984) in his research postulated however that, as long as a consumer feels dissatisfied, it will trigger an act of complaining, because as long as the consumer's virtue about a seller is not high enough dissatisfaction can set in. Therefore, a consumer's emotion prior to the use of a product is strongly and positively related to satisfaction.

\subsubsection{Trust}

Prior to the purchase of a product, most consumers have some level of expectations as to the level of satisfaction of the product. However, if it does not go accordingly after usage, there tend to be dissatisfaction. Most literature on consumer trust connects it with loyalty. As a result of uncertainty and risks, trust has become a very crucial topic being discussed in recent literature. Several marketing literature links consumer trust and satisfaction. In their research, Dwyer et al. concluded that trust and satisfaction are related in a good way. In view of this, forecasted that it is better for a consumer to have a higher opinion about a seller since it is more persuading than the vice versa. From the above literature, one can clearly point out that a consumer's trust prior to the use of a product is positively related to the dissatisfaction level. The lower the trust, the higher the dissatisfaction level in the product.

\subsubsection{Negative disconfirmation}

Disconfirmation refers to an instance when a consumer has a set of beliefs as to how a product or service should work out prior to usage. After usage, if the consumer is highly satisfied it means disconfirmation is positive. If the consumer however becomes disappointed, the disconfirmation is negative, hence dissatisfaction, and in most cases negative disconfirmation increases dissatisfaction. Even though researches on satisfaction stresses disconfirmation as a very important and central variable, Oliver (1977) suggested that one should ascertain expectations and disconfirmation differently as he posited that disconfirmation does not control satisfaction in any way. Prior literature on disconfirmation focused on how one's expectations, disconfirmations and level of satisfaction are related to one another.

\subsection{Responses to consumer dissatisfaction}

This section discusses four main behaviors that consumers demonstrate when faced with dissatisfactory experiences with a product. These include Negative WOM, Switching, Complaints and No co-creation intentions. Others describe negative WOM as "interpersonal communication among consumers concerning a marketing organization or product which denigrates the object of the communication".

Another response to consumer dissatisfaction is to switch products. This behavior is defined as the demeanor that consumers show in relation to their "satisfactory level". Therefore the more dissatisfied they are, the more easily and faster it becomes for them to switch to other competitor brands, notwithstanding their level of loyalty to the company. The third response to dissatisfaction is complaints. Some scholars defined complaint as violating a situation that a consumer anticipates to achieve. Complaint can also be defined as when a consumer shows any 
sign of dissatisfaction and hostility. The focal point of consumer complaining behavior is dissatisfaction, which eventually helps companies on ways to correct all errors and mistakes

The final response to dissatisfaction is 'no intention to co-create'. Co-creation is about involving consumers actively in the production process and allowing them to use their discretion. In a broader sense, co-creation can be explained as a phenomenon where consumers create value. Initially, it was the company who determined what value is, however, the emergence of cocreation came to redefine value in that, consumers and the company act together (Ind and Coates, 2013). Consumer dissatisfaction can influence a person's willingness to co-create. In most cases, consumers who are dissatisfied are not willing to co-create.

\section{The impact of consumer dissatisfaction}

Most consumer satisfaction literature is based on Oliver's findings that suggested that the results a consumer gets after using a product is not in any way related to what the consumer expects to achieve prior to purchasing, that is disconfirmation. A greater number of consumers become dissatisfied especially with a company based on several disconfirmation experiences and most especially when a consumer feels the quality of a product and/or service is constantly deteriorating. Ferguson \& Johnston (2011) concluded even though dissatisfaction is irrefutable, companies can dwell on the conduct of dissatisfied consumers and try to solve the effect dissatisfaction has on consumers (Ferguson and Johnston, 2011). Their research also stipulated that the consanguinity between the company and the consumer can affect the action exhibited by the consumer during dissatisfaction. This means the more years a consumer has with a company or supplier can affect the way they react or respond to dissatisfaction in the business-to-business setting. Even though most research focuses on satisfaction responses, the few research that discussed dissatisfaction did not delve much into the entire manner in which consumers behave when dissatisfied.

\section{Theoretical and managerial implications}

\subsection{Theoretical implications}

Consumer dissatisfaction is an unavoidable phenomenon in every business environment. In view of this, every company should make it a point to please their customers. Although practically this is not possible, companies can still try their best to render better services to consumers as they are the backbone to their profit margins. The research of Zeelenberg \& Pieters (2004) used the "valence-based approach and the "specific emotions approach" to conclude that dissatisfaction mainly occurs when emotions are hostile. And this means that the reason for dissatisfaction needs a little bit of in-depth analysis.

\subsection{Managerial implications}

Dissatisfaction can cause very severe damaging effects on a company. Therefore, managers can persuade consumers to voice out their dissatisfaction in a cordial manner instead of using harsh ways such as negative WOM, switching and not engaging in co-creation.

Managers can as well create a platform for consumers to voice out their dissatisfactory experiences and ensure that complaints are dealt with appropriately so as to address consumer problems because dissatisfaction can cause a consumer to switch products which can affect the 
profit margin of the company. Dissatisfaction tends to increase when the company is silent on consumer complaints. Negative WOM also has a way of affecting the company's integrity that has been built over a period of time. Therefore addressing consumer dissatisfactory experiences can reduce or eliminate negative WOM.

In addition, managers should always ensure that consumer problems are addressed on time and in a proper manner. As the saying goes, "the customer is always right". This can be done by setting up a team to solely oversee such complaints from customers. Though it can bring about extra costs, it is worth it as consumers are very essential for every business organization in terms of profit margin. Managers could as well find other ways to compensate consumers who have not been satisfied in the process. This could be in a form of granting discounts, offering free delivery, etc. as this will encourage such consumers to feel special and engage in co-creation activities.

\section{Conclusion and future research}

This research contributed to existing literature on consumer dissatisfaction. A consumer may be dissatisfied based on a number of reasons prior to purchase, during consumption and after consumption. However, upon dissatisfaction, consumers have every right to complain and make companies and suppliers aware of their disappointment. If companies are able to respond positively to their complaints, consumers will be willing to go further transacting business with the company (Trawick and Swan, 1981). On the contrary, when nothing is done about the situation, consumers go further to exhibit dissatisfactory behaviors such as negative WOM, switch, complain or not engage in any co-creation activities. Since most research on consumer dissatisfaction focuses on the hospitality sector, mostly restaurants and hotels, and few in the health sector further studies can focus on dissatisfactory behaviors in everyday consumer goods.

Again most research administer questionnaires that incorporates simple 'yes' and 'no' answers. For lack of space, consumers are not able to express the proper level of dissatisfaction as well as their true feelings about the product; in this regard methods such as personal interviews will work well to reveal the true feelings of the consumer.

\section{Acknowledgements}

The authors would like to thank the National Natural Science Foundation of China for providing funds for this research.

\section{References}

ANTÓN, C., CAMARERO, C. \& CARRERO, M. 2007. Analysing firms' failures as determinants of consumer switching intentions: the effect of moderating factors. European Journal of Marketing, 41, pp $135-158$.

BALAJI, M., WEI, K. K. \& CHONG, A. Y. L. 2016. Determinants of Negative Word-of-Mouth Communication using Social Networking Sites. Information \& Management.

BODUR, M. 1977. Satisfaction, dissatisfaction and complaining behavior with consumer services and intangible products. Indiana University. 
BUTTLE, F. A. 1998. Word of mouth: understanding and managing referral marketing. Journal of strategic marketing, 6, pp. 241-254.

CADOTTE, E. R. \& TURGEON, N. 1988. Dissatisfiers and satisfiers: suggestions from consumer complaints and compliments. Journal of consumer satisfaction, Dissatisfaction and Complaining Behavior, 1, pp. 74-79.

CASIDY, R. \& SHIN, H. 2015. The effects of harm directions and service recovery strategies on customer forgiveness and negative word-of-mouth intentions. Journal of Retailing and Consumer Services, 27, pp. 103-112.

CHIH, W.-H., WANG, K.-Y., HSU, L.-C. \& CHENG, I.-S. 2012. From disconfirmation to switching: an empirical investigation of switching intentions after service failure and recovery. The Service Industries Journal, 32, pp. 1305-1321.

COLQUITT, J. A. 2004. Does the justice of the one interact with the justice of the many? Reactions to procedural justice in teams. Journal of Applied Psychology, 89, 633.

DAY, G. S. 1971. Attitude change, media and word of mouth. Journal of Advertising Research.

FERGUSON, J. L. \& JOHNSTON, W. J. 2011. Customer response to dissatisfaction: A synthesis of literature and conceptual framework. Industrial Marketing Management, 40, pp. 118-127.

G NEJAD, M., AMINI, M. \& SHERRELL, D. 2015. The Profit Impact of Revenue Heterogeneity and Assortativity in the Presence of Negative Word-of-Mouth. Nejad, Mohammad G., Mehdi Amini, and Daniel L. Sherrell (2016), "The Profit Impact of Revenue Heterogeneity and Assortativity in the Presence of Negative Word-of-Mouth,” International Journal of Research in Marketing, p. 33.

GARRETT, D. E. \& TOUMANOFF, P. G. 2010. Are consumers disadvantaged or vulnerable? An examination of consumer complaints to the better business bureau. Journal of Consumer Affairs, 44, pp. 3-23.

HANSEN, T., WILKE, R. \& ZAICHKOWSKY, J. 2010. Managing consumer complaints: differences and similarities among heterogeneous retailers. International Journal of Retail \& Distribution Management, 38, pp. 6-23.

IND, N. \& COATES, N. 2013. The meanings of co-creation. European Business Review, 25, pp. 86-95.

JANG, Y. J. \& KIM, W. G. 2011. The Role of Negative Emotions in Explaining Restaurant Customer Dissatisfaction and Behavioral Intention.

JONES, M. A., MOTHERSBAUGH, D. L. \& BEATTY, S. E. 2000. Switching barriers and repurchase intentions in services. Journal of retailing, 76, pp. 259-274.

LANDON JR, E. L. Consumer satisfaction research orientation. Differences between industry and government. Conceptualisation an measurement of consumer satisfaction and disatisfaction. Proceedings of conference conducted by Marketing Science Institute, report, 1977. pp. 77-103. 
LOVEMAN, G. W. 1998. Employee satisfaction, customer loyalty, and financial performance an empirical examination of the service profit chain in retail banking. Journal of Service Research, 1, pp. 1831.

OLIVER RICHARD, L. 1997. Satisfaction: A behavioral perspective on the consumer. New York ' NY: Irwin-McGraw-Hill.

OLIVER, R. L. 1997. Satisfaction: A behavioral perspective on the customer. New York.

RICHINS, M. L. 1983. Negative word-of-mouth by dissatisfied consumers: A pilot study. The journal of marketing, pp. 68-78.

SHETH, J. N. 1971. Word-of-mouth in low-risk innovations. Journal of Advertising Research, 11, 15-18.

SLOOT, L. M. \& VERHOEF, P. C. 2008. The impact of brand delisting on store switching and brand switching intentions. Journal of Retailing, 84, pp. 281-296.

STERN, B. B. 1994. A revised communication model for advertising: Multiple dimensions of the source, the message, and the recipient. Journal of Advertising, 23, pp. 5-15.

TRAWICK, I. F. \& SWAN, J. E. 1981. A model of industrial satisfaction/complaining behavior. Industrial Marketing Management, 10, pp. 23-30.

WEBSTER, C. \& SUNDARAM, D. 1998. Service consumption criticality in failure recovery. Journal of Business Research, 41, pp. 153-159.

WIRTZ, J., BRAH, S., YANAMANDRAM, V. \& WHITE, L. 2006. Switching barriers in business-tobusiness services: a qualitative study. International Journal of Service Industry Management, 17, pp. 158192.

XIA, L., MONROE, K. B. \& COX, J. L. 2004. The price is unfair! A conceptual framework of price fairness perceptions. Journal of marketing, 68, pp. 1-15.

YADAV, M. S. \& PAVLOU, P. A. 2014. Marketing in computer-mediated environments: Research synthesis and new directions. Journal of Marketing, 78, pp. 20-40.

ZEELENBERG, M. \& PIETERS, R. 2004. Beyond valence in customer dissatisfaction: A review and new findings on behavioral responses to regret and disappointment in failed services. Journal of business Research, 57, pp. 445-455. 